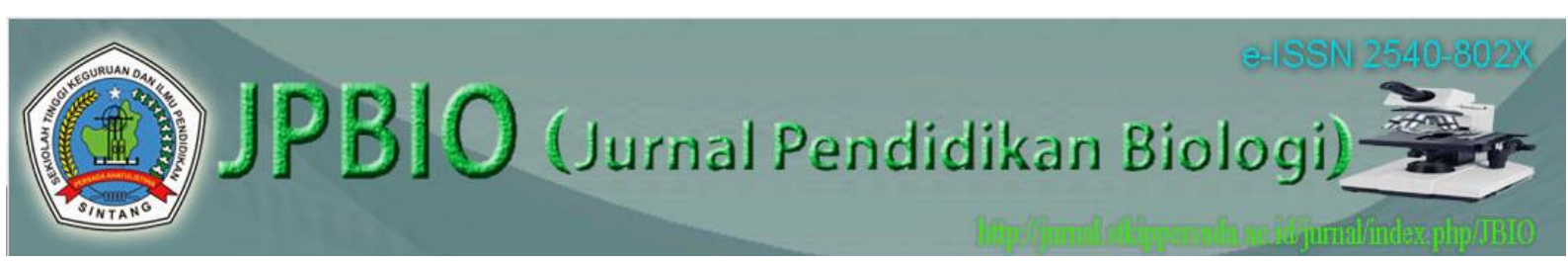

JPBIO (Jurnal Pendidikan Biologi)

Vol. 2 No. 1 April 2017 | 26-31

ISSN 2540-802x (Online)

DOI: http://dx.doi.org/10.31932/ JPBIO (Jurnal Pendidikan Biologi)

http://jurnal.stkippersada.ac.id/jurnal/index.php/JBIO

\title{
PENGARUH MODEL PEMBELAJARAN SCRAMBLETERHADAP HASIL BELAJAR SISWA PADA MATERI KINGDOM ANIMALIA DI KELAS X SEKOLAH MENENGAH ATAS NEGERI 2 SINTANG
}

\author{
Rhahman Hadi ${ }^{1}$, Didin Syafrudin ${ }^{2^{*}}$, Florentina Rahayu Esti Wahyuni ${ }^{3}$ \\ ${ }^{1}$ Mahasiswa Program Studi Pendidikan Biologi, STKIP Persada Khatulistiwa Sintang \\ ${ }^{2,3}$ Dosen Program Studi Pendidikan Biologi, STKIP Persada Khatulistiwa Sintang \\ E-mail:Rhahmanhadi@ymail.com, didin_saprudin28@yahoo.com*, \\ esti_pandi@ymail.com
}

Diterima: 24 Februari 2017

Direvisi: 11 Maret 2017

Disetujui: 29 Maret 2017

\begin{abstract}
ABSTRAK
Penelitian ini bertujuan Untuk Mengetahui Pengaruh Model Pembelajaran Scramble Terhadap Hasil Belajar Siswa Pada Materi Kingdom Animalia di kelas X Sekolah Menengah Atas Negeri 2 Sintang". Bentuk penelitian ini adalah eksperimen semu (quasi eksperimental design) dengan desain penelitian Control Group Pretest- Postest Design. Populasi penelitian ini berjumlah 200 siswa. Teknik pengambilan sampelnya menggunakan Purposive Sampling dengan jumlah 64 siswa. Alat pengumpul datanya adalah lembar observasi, soal tes, dan angket respon siswa. Teknik pengolahan data menggunakan uji Z Parametrik karena data berdistribusi normal dan memiliki data yang homogen. Dari hasil uji hipotesis diketahui bahwa nilai $\left(Z_{\text {hitung }}=-3,97, Z_{\text {tabel }}=0,4750\right)$ maka $H_{0}$ diterima. Kesimpulan dari hasil penelitian ini adalah Tidak Terdapat Pengaruh yang signifikan Model Pembelajaran Scramble terhadap hasil belajar Siswa pada materi Kingdom Animalia di kelas X Sekolah Menengah Atas Negeri Dua Sintang.
\end{abstract}

Kata kunci: Model Pembelajaran Scramble, Hasil Belajar.

\section{ABSTRACT}

This research aimed to find out the effect of scramble learning model to the student's achievement at kingdom animalia material at class X SMAN 2 Sintang. Quasy experimental design was implemented in this research with the stages were control group PretestPosttest design. The sample of this research was 200 students. The sampling collecting technique used purposive sampling on 64 students. The tools were observation sheet, test, and questionnaire. $Z$ parametric test was implemented in this research due to the data normal and homogeny distributed. The hypothesis test result showed that $(\boldsymbol{Z}$ count $=-3,97, \boldsymbol{Z}$ table $=0,4750)$ so $H_{0}$ confirmed. The hypotthesis it could be concluded that there was no significant side effect of scramble learning model to the student's achievement at kingdom animalia material at class $X$ SMAN 2 Sintang.

Keywords: Scramble learning model, Learning Achievement

JPBIO, Vol. 2, No. 1, April 2017: 26 - 31 


\section{PENDAHULUAN}

Hakekat Pembangunan Nasional adalah membangun manusia Indonesia yang seutuhnya dan pembangunan masyarakat dengan memperhatikan perkembangan pendidikan dunia yang begitu pesat, maka pembentukan masyarakat Indonesia yang modern ini akan menyangkut perubahan-perubahan nilai dan sikap. Perubahan dapat diperoleh melalui proses pembinaan anak seusia sekolah melalui berbagai macam pendidikan. Sebagaimana yang telah dijabarkan dalam Undang-Undang Sistem Pendidikan Nasional No 20 Tahun 2003 (Hanafiah dan Suhana, 2010: 20) yang menyatakan bahwa, Pendidikan adalah usaha sadar dan terencana untuk mewujudkan suasana belajar dan proses pembelajaran agar peserta didik secara aktif mengembangkan potensi dirinya untuk memiliki kekuatan spiritual keagamaan, pengendalian diri, kepribadian, kecerdasan, dan akhlak mulia, serta keterampilan yang diperlukan dirinya, masyarakat, bangsa, dan negara.

Permasalahan tersebut dapat diatasi jika guru dapat melakukan proses pembelajaran yang lebih kreatif dan menggunakan strategi yang tepat, agar materi yang disampaikan mudah untuk diterima oleh siswa. Salah satunya dengan menerapkan model pembelajaran yang dapat mendorong siswa untuk dapat berperan aktif dalam proses pembelajaran dan dapat meningkatkan hasil belajar siswa diantaranya model pembelajaran Scramble, pembelajaran Scramble merupakan suatu permainan acak kata dalam suatu kelompok yang menekankan kerjasama siswa, meningkatkan keaktifan siswa dalam menyelesaikan suatu masalah, mempermudah siswa dalam belajar serta memahami suatu konsep pembelajaran.

Menurut (Wintervina, 2012): Aplikasi permainan yang tepat pada proses pembelajaran antara lain dapat menciptakan hubungan belajar yang lebih fleksibel antara siswa, memecahkan kebekuan antara siswa dan guru sehingga para guru bisa benar-benar berperan selayaknya teman belajar dan melatih berbagai kecakapan berpikir tanpa mesti terbebani dan susah payah.

"Pembelajaran Scramble dilakukan dengan membagikan kartu soal dan kartu jawaban yang disertai dengan alternatif jawaban yang tersedia namun dengan susunan yang acak dan siswa bertugas mengoreksi jawaban tersebut sehingga menjadi jawaban yang tepat

(Nur, 2011:21)". Selanjutnya menurut Hanafiah dan Suhana (Nur, 2011: 18) "Model pembelajaran scramble bersifat aktif, siswa dituntut aktif bekerja sama serta bertanggung jawab terhadap kelompoknya untuk menyelesaikan kartu soal guna memperoleh poin dan diharapkan dapat meningkatkan kebersamaan siswa".

Menurut Suyatno (lis, 2011: 13) menyebutkan tahapan pembelajaran Scramble adalah sebagai berikut. 1) Membuat kartu soal sesuai materi ajar. 2) Guru membuat soal sesuai dengan materi yang akan disajikan kepada siswa. 3) Membuat kartu jawaban dengan diacak. Guru membuat pilihan jawaban yang susunannya diacak sesuai jawaban soal-soal pada kartu soal. 1) Sajikan materi. 2) Guru menyajikan materi ajar kepada siswa. 3) Bagikan kartu soal dan kartu jawaban pada kelompok. 4) Guru membagikan kartu soal dan membagikan kartu jawaban sebagai pilihan jawaban soal-soal pada kartu soal. 5) Siswa berkelompok mengerjakan kartu soal. 6) Siswa berkelompok dan saling membantu mengerjakan soal-soal yang ada pada kartu soal. 7) Siswa mencari jawaban untuk setiap soal-soal dalam kartu soal. 8) Siswa mencari jawaban yang cocok untuk setiap soal yang mereka kerjakan dan memasangkannya pada kartu soal.

Hasil belajar menurut Suprijono (2012: 5) adalah pola-pola perbuatan, nilai-nilai, pengertian-pengertian, sikap-sikap, apresiasi, dan keterampilan". Dari pengertian diatas dapat disimpulkan bahwa hasil belajar yang diperoleh dalam proses belajar adalah suatu nilai akhir yang diperoleh siswa setelah menerima suatu pembelajaran". Perubahan yang dapat terjadi dengan penggunaan model pembelajaran ini adalah siswa dapat lebih aktif dalam bekerja sama dengan temannya sehingga teman yang tahu dan paham tentang materi tersebut dapat mengajarkan kepada temannya yang tidak tahu itu. Proses pembelajaran ini dapat membantu seorang pendidik dalam kegiatan pembelajaran pada saat itu. Penggunaan model pembelajaran ini membantu peserta didik dalam menambah kosa katanya tentang materi pembelajaran yang disampaikan oleh pendidik, sehingga akan 
mempengaruhi hasil belajar siswa. Menyikapi uraian yang ada diatas maka peneliti tertarik untuk mengatasi permasalahan tersebut melalui suatu model pembelajaran dengan judul penelitian "Pengaruh Model Pembelajaran Scramble Terhadap Hasil Belajar Siswa Pada Materi Kingdom Animalia di Kelas X Sekolah Menengah Atas Negeri 2 Sintang".

\section{METODE PENELITIAN}

Metode penelitian yang digunakan dalam penelitian ini berupa metode eksperimen semu (quasi eksperimental). Dengan rancangan (Control Group Pretest- Postest Design), rancangan tersebut dapat dilihat pada Tabel 1.

Tabel 1. Rancangan Penelitian Control Group Pretest- Postest Design

\begin{tabular}{cccc}
\hline Group & Pretest & Treatment & Post-test \\
\hline Kelas Eksperimen & $\mathrm{O}_{1}$ & $\mathrm{X}$ & $\mathrm{O}_{2}$ \\
\hline Kelas Kontrol & $\mathrm{O}_{3}$ & - & $\mathrm{O}_{4}$ \\
\hline & & Sumber: Arikunto $(2010: 124)$
\end{tabular}

Keterangan:

$\mathrm{O}_{1}, \mathrm{O}_{3}$ : Tes awal kelompok eksperimen,

$\mathrm{O}_{2}, \mathrm{O}_{4}$ : Tes akhir kelompok eksperimen

$\mathrm{X} \quad$ : Pelakuan untuk kelompok eksperimen dengan menggunakan Model Pembelajaran Scramble,

- $\quad$ : Perlakuan untuk kelompok kontrol dengan menggunakan metode pembelajaran Konvensional

Populasi dalam penelitian ini adalah seluruh siswa kelas X Sekolah Menengah Atas Negeri 2 Sintang yang berjumlah 200 siswa. Sampel dalam penelitian ini berjumlah 64 siswa yang diambil dengan teknik (Purposive Sampling). Teknik ini dilakukan atas dasar jumlah siswa yang sama, nilai terendah dari siswa kelas X di Sekolah Menengah Atas Negeri 2 Sintang. Data penelitian bersumber dari perolehan hasil belajar siswa dalam pembelajaran menggunakan model pembelajaran Scramble yang diukur melalui tes hasil belajar yang sudah melalui uji coba instrumen. Tes hasil belajar yang digunakan dalam penelitian ini berbentuk tes objektif sebanyak 20 butir soal. Data selanjutnya dianalisis dengan menggunakan metode statistik parametrik yaitu uji-Z.

\section{HASIL PENELITIAN}

Data penelitian ini adalah skor hasil belajar siswa sebagai akibat dari pembelajaran dengan model pembelajaran Scramble pada kelompok eksperimen dan pembelajaran konvensional pada kelompok kontrol. Rekapitulasi perhitungan data hasil belajar siswa dapat dilihat pada Tabel 2.

Tabel 2. Rekapitulasi hasil perhitungan skor hasil belajar siswa

\begin{tabular}{lcc}
\hline \multirow{2}{*}{ Data Statistik } & \multicolumn{2}{c}{ Hasil Belajar } \\
\cline { 2 - 3 } & Kelompok Eksperimen & Kelompok Kontrol \\
\hline Mean & 53,82 & 57,79 \\
\hline Median & 52,5 & 57,5 \\
\hline Modus & 55 & $55,60,65$ \\
\hline Varians & 84,94 & 57,86 \\
\hline Standar deviasi & 9,21 & 7,61 \\
\hline Skor maksimum & 70 & 70 \\
\hline Skor minimum & 35 & 35 \\
\hline Rentangan & 35 & 35 \\
\hline
\end{tabular}

Data hasil belajar kelompok eksperimen dalam pembelajaran dengan menggunakan model pembelajaran Scramble dapat disajikan ke dalam bentuk grafik histogram seperti pada Gambar 1. 


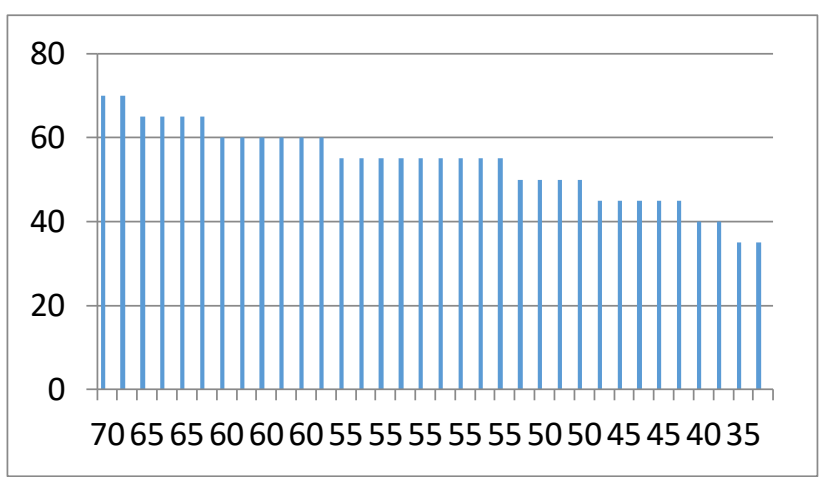

Gambar 1. Histogram Data Hasil Post-test Kelompok Eksperimen

Data hasil belajar kelompok kontrol dalam pembelajaran dengan menggunakan model pembelajaran konvensional, dapat disajikan kedalam bentuk grafik histogram seperti pada Gambar 2.

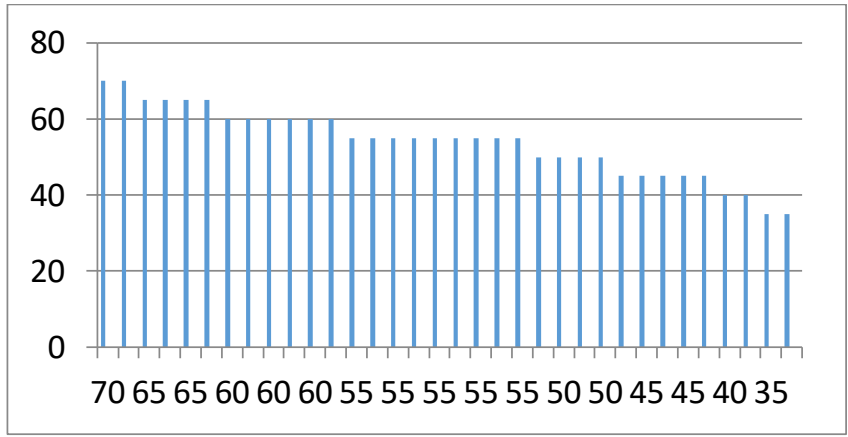

Gambar 2. Histogram Data Hasil Post-test Kelompok Kontrol

Berdasarkan hasil perhitungan uji normalitas yaitu data berditribusi normal dengan jumlah siswa 34 orang, maka uji hipotesis menggunakan statistik parametrik yaitu uji hipotesis menggunakan uji $Z$ parametrik. Adapun hasil uji $Z$ yang diperoleh dapat dilihat dalam Tabel 3 berikut ini:

Tabel 3.Hasil uji hipotesis dengan uji Z

\begin{tabular}{cccccc}
\hline $\begin{array}{c}\text { Kel } \\
\text { as }\end{array}$ & $\mathbf{N}$ & $\begin{array}{c}\text { Rera } \\
\text { ta } \\
\text { post } \\
\text { test }\end{array}$ & $\begin{array}{c}\mathbf{Z}_{\text {tabel }} \boldsymbol{\alpha}(\boldsymbol{)}) \\
\mathrm{Z}_{\text {hitu }}\end{array}$ & $\begin{array}{c}\text { Keteran } \\
\text { gan }\end{array}$ \\
\hline $\mathrm{XA}$ & 3 & $\begin{array}{c}53,8 \\
2\end{array}$ & 0,4750 & $-3,97$ & $\begin{array}{c}\text { Tidak } \\
\text { terdapat } \\
\text { pengaru } \\
\mathrm{h}\end{array}$ \\
\hline
\end{tabular}

Diketahui bahwa nilai $Z_{\text {hitung }}$ adalah $-3,97$ sedangkan nilai $Z_{\text {tabel }}$ pada $\alpha=5 \%$. hal ini berarti nilai $Z_{\text {hitung }}$ lebih kecil dari $Z_{\text {tabel }}\left(Z_{\text {hitung }}<Z_{\text {tabel }}\right)$ sehingga $\mathrm{H}_{0}$ diterima dan $\mathrm{H}_{1}$ ditolak. Dengan demikian, dapat diinterpretasikan bahwa tidak terdapat pengaruh model pembelajaran Scramble terhadap hasil belajar siswa pada materi kingdom animalia.

\section{PEMBAHASAN}

Pembahasan pada penelitian ini memaparkan hasil belajar Biologi siswa baik pada kelompok yang belajar menggunakan model pembelajaran Scramble maupun dengan siswa yang belajar menggunakan model pembelajaran konvensional. Hasil penelitian ini 
menunjukkan bahwa hasil belajar siswa yang dicapai dengan menggunakan model pembelajaran Scramble tidak memiliki pengaruh yang signifikan. Perbandingan hasil posttest pada kelas eksperimen dan kelas kontrol dapat dilihat pada Gambar 4.3 berikut ini:

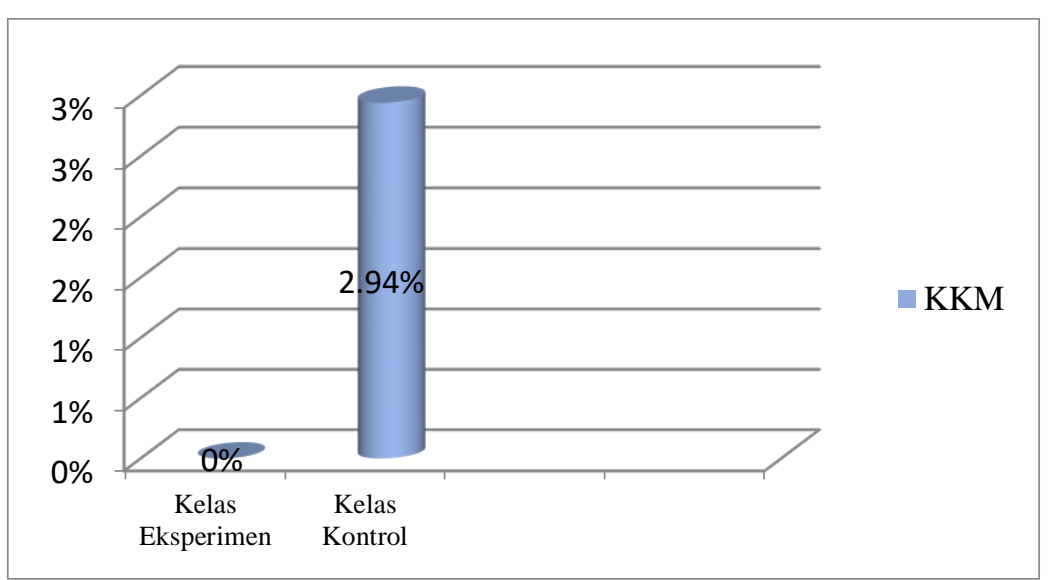

Gambar 3. Perbandingan Hasil Posttest Pada Kelas Eksperimen dan Kelas Kontrol

Hasil uji statistik parametrik yaitu uji Z karena data berdistribusi normal dan jumlah siswa 34 orang. Hal ini dikarenakan model pembelajaran ini mengutamakan adanya kerjasama antar kelompok dalam menyusun kembali kata yang telah diacak, menuntut siswa untuk lebih banyak menguasai nama-nama ilmiah dalam materi Kingdom Animalia sehingga dapat menyusun jawaban yang tepat, menuntut siswa untuk berpikir kreatif, dan dapat bekerjasama dengan baik dalam memecahkan masalah bersama-sama.

Secara operasional model pembelajaran Scramble terdiri dari beberapa langkah1) Guru membuat soal sesuai dengan materi yang akan disajikan kepada siswa. 2) Guru membuat pilihan jawaban yang susunannya diacak sesuai jawaban soal-soal pada kartu soal. 3) Guru menyajikan materi ajar kepada siswa. 4) Guru membagikan kartu soal dan membagikan kartu jawaban sebagai pilihan jawaban soal-soal pada kartu soal. 5) Siswa berkelompok dan saling membantu mengerjakan soal-soal yang ada pada kartu soal. 6) Siswa mencari jawaban yang cocok untuk setiap soal yang mereka kerjakan dan memasangkannya pada kartu soal. Langkah-langkah pembelajaran dengan model pembelajaran Scramble sangat mengutamakan peran dan aktivitas siswa dalam pembelajaran. Guru hanya berperan sebagai fasilitator seperti menyediakan sumber-sumber belajar yang dapat membantu siswa dalam memahami materi pembelajaran selain buku paket, media dan LKS, guru juga sebagai mediator atau pengarah untuk membantu siswa dalam mengkaji pengetahuannya sendiri sebagai acuan untuk memahami materi yang dibahas di kelas. Siswa dituntut bekerjasama dengan kelompoknya, ini menekankan ada interaksi yang dibangun oleh diri siswa yang akan menjadi saling bertukar pendapat. Berbeda dengan model pembelajaran konvensional. Model pembelajaran konvensional lebih menekankan pada aktivitas guru (teacher centered).

Berdasarkan pemaparan di atas tentang model pembelajaran Scramble dan model pembelajaran konvensional dapat dilihat bahwa secara konseptual dan operasional antara kedua model tersebut terdapat perbedaan yang jelas. Dalam penelitian ini terdapat beberapa keterbatasan yang menjadi hambatan dalam penelitian ini, antara lain sebagai berikut; Pada saat dilaksanakan kegiatan pembelajaran, terdapat beberapa orang siswa yang bermain sendiri, sehingga pada saat pemberian lembar kerja dan tes siswa memperoleh hasil belajar yang rendah. Memerlukan pengawasan yang ketat dari seorang guru dalam mengkondisikan kelas agar pelaksanaan pembelajaran dapat berjalan secara baik dan sesuai dengan strategi pembelajaran. Antara siswa sering mengganggu sesama temannya pada saat pembelajaran berlangsung. Model pembelajaran Word Scramble adalah penyusunan kembali kata oleh kelompok yang telah diacak dan disesuaikan dengan lembar soal agar dapat menjawab dengan benar tetapi pada pelaskanaannya siswa lebih banyak bermain dan ada yang mencontek jawaban temannya yang lebih dianggap pintar. Hasil penelitian ini kurang sejalan dengan penelitian yang dilakukan oleh peneliti sebelumnya. Susi Mariati (2012) menyatakan 
bahwa, Peningkatan hasil belajar diperoleh kriteria yang sangat memuaskan. Sri Handayani (2015) diketahui dari nilai thitung yang diperoleh, dimana thitung lebih besar dari $t_{\text {tabel }}$ $(4,44>1.99)$. Dengan demikian, hipotesis Ha diterima, yaitu terdapat pengaruh model pembelajaran Scramble terhadap hasil belajar siswa pada materi keanekaragaman makhluk hidup kelas VII di SMP Negeri 2 Satu Atap Kepenuhan Hulu tahun pembelajaran 2014/2015. Implikasi temuan penelitian ini adalah Model pembelajaran Scramble tidak memiliki pengaruh yang signifikan pada hasil belajar siswa.

\section{SIMPULAN}

Berdasarkan hasil penelitian, dan pembahasan dalam penelitian ini, dapat disimpulkan bahwa Tidak terdapat pengaruh yang signifikan pada hasil belajar siswa karena diperoleh nilai rata-rata 53,82 pada kelas eksperimen dan pada kelas kontrol diperoleh nilai rata-rata 57,79

\section{REFERENSI}

Arikunto, S. 2010. Prosedur Penelitian Suatu Pendekatan Praktik. Jakarta: PT. Rineka Cipta.

lis Widayanti. (2011). Penerapan Model Pembelajaran Kooperatif Tipe Scramble Untuk Meningkatkan Hasil Belajar Siswa Pada Mata Pelajaran Teknologi Informasi Dan Komunikasi. Diakses dari http://repository.upi.edu/operator/upload/pdf pada tanggal 14 Maret 2012.

Mariati, S. (2012). Upaya meningkatkan motivasi dan hasil belajar siswa melalui model Scramble pada materi keragaman pada sistem organisasi kehidupan di kelas VII B Sekolah Menengah Pertama Panca Setya I Sintang Tahun pelajaran 2012/2013. Skripsi tidak diterbitkan. Sintang: Sekolah Tinggi Keguruan dan Ilmu Pendidikan Persada Khatulistiwa Sintang.

Nur Malechah. (2010). Perbandingan Hasil Belajar Siswa Dengan Menggunakan Model Pembelajaran Course Review Horey (CRH) Dan Model Pembelajaran Scramble Berbantuan LKS Pada Pokok Bahasan Bangun Datar Siswa Kelas VII Semester II SMP N 2 Sayung Demak Tahun Pelajaran 2010/2011. Skripsi tidak diterbitkan Semarang: Jurusan Pendidikan Matematika Universitas PGRI Semarang.

Sri Handayani. (2015). Pengaruh model pembelajaran Scramble terhadap hasil belajar siswa kelas VII di Sekolah Menengah Pertama Negeri 2 satu atap Kepenuhan hulu. Skripsi tidak diterbitkan Jurusan Program Studi Pendidikan Biologi, Fakultas Keguruan dan Ilmu Pendidikan, Universitas Pasir Pengaraian.

Suprijono, A. (2012). Cooperative Learning Teori dan Aplikasi PAIKEM. Yogyakarta: Pustaka Belajar.

Wintervina. (2012). Model Pembelejaran Tebak kata. (online). Tersedia: http://Wintevina. Blogspot. Com/2012/05/model-pembelajaran-tebak-kata.html. (18 November 2013) 